\title{
RESEARCH
}

Open Access

\section{The effects of dyslipidaemia and cholesterol modulation on erythrocyte susceptibility to malaria parasite infection}

Marion Koch', Jaimini Cegla², Ben Jones², Yuning Lu ${ }^{3}, Z^{2}$ iad Mallat ${ }^{3}$, Andrew M. Blagborough 1,4, Fiona Angrisano ${ }^{1,4}$ and Jake Baum ${ }^{1 *}$ (D)

\begin{abstract}
Background: Malaria disease commences when blood-stage parasites, called merozoites, invade human erythrocytes. Whilst the process of invasion is traditionally seen as being entirely merozoite-driven, emerging data suggests erythrocyte biophysical properties markedly influence invasion. Cholesterol is a major determinant of cell membrane biophysical properties demanding its interrogation as a potential mediator of resistance to merozoite invasion of the erythrocyte.
\end{abstract}

Methods: Biophysical measurements of erythrocyte deformability by flicker spectroscopy were used to assess changes in erythrocyte bending modulus on forced integration of cholesterol and how these artificial changes affect invasion by human Plasmodium falciparum merozoites. To validate these observations in a natural context, either murine Plasmodium berghei or human Plasmodium falciparum merozoites were tested for their ability to invade erythrocytes from a hypercholesterolaemic mouse model or human clinical erythrocyte samples deriving from patients with a range of serum cholesterol concentrations, respectively.

Results: Erythrocyte bending modulus (a measure of deformability) was shown to be markedly affected by artificial modulation of cholesterol content and negatively correlated with merozoite invasion efficiency. In an in vitro infection context, however, erythrocytes taken from hypercholesterolaemic mice or from human clinical samples with varying serum cholesterol levels showed little difference in their susceptibility to merozoite invasion. Explaining this, membrane cholesterol levels in both mouse and human hypercholesterolaemia erythrocytes were subsequently found to be no different from matched normal serum controls.

Conclusions: Based on these observations, serum cholesterol does not appear to impact on erythrocyte susceptibility to merozoite entry. Indeed, no relationship between serum cholesterol and cholesterol content of the erythrocyte is apparent. This work, nonetheless, suggests that native polymorphisms which do affect membrane lipid composition would be expected to affect parasite entry. This supports investigation of erythrocyte biophysical properties in endemic settings, which may yet identify naturally protective lipid-related polymorphisms.

Keywords: Plasmodium falciparum, Red blood cell, Host-parasite interactions, Flicker microscopy, Membrane biophysics, Merozoite

\footnotetext{
*Correspondence: jake.baum@imperial.ac.uk

${ }^{1}$ Department of Life Sciences, Imperial College London, Exhibition Road,

South Kensington, London SW7 2AZ, UK

Full list of author information is available at the end of the article
} 


\section{Background}

Cholesterol is a key constituent of human cells and plays a key role in modulating membrane properties, influencing both membrane fluidity [1] and stiffness [2, 3]. The effect on these cellular properties is mediated by cholesterol's flat rigid structure which is defined by the planar tetracyclic ring shape of the molecule. While an elevation in the cholesterol content contained within cell membranes is expected to lead to a reduction in cell elasticity, how these levels are regulated and how dynamic they are in human erythrocytes remains largely unknown. A significant change in plasma lipid levels is medically described as dyslipidaemia, a term used to categorize a number of conditions, including hypercholesterolaemia, which is associated with an increase in plasma cholesterol levels. Importantly, whether and how such an increase in plasma cholesterol would affect cellular membrane composition is not clear. For example, a number of studies have found differences in how treatment of elevated plasma cholesterol or clinical conditions with dyslipidaemia is associated with differences in erythrocyte membrane cholesterol levels [4-6].

Erythrocyte infection lies at the heart of all symptoms of malaria disease. It is established when the blood-stage merozoite form of the Plasmodium parasite attaches to and penetrates the erythrocyte with concomitant formation of a parasitophorous vacuole inside [7]. There is a detailed appreciation of the stepwise molecular events that characterize merozoite invasion [8], however, the role the erythrocyte plays in the process was, up until recently, largely overlooked [9]. There has been a growing appreciation in the past few years that parasite binding to the erythrocyte, stimulates biophysical changes in the red cell that likely facilitate entry making it energetically more favourable [10, 11]. Further, several key polymorphisms that protect against malaria infection may do so directly by modulating erythrocyte biophysical properties [12, 13]. These polymorphisms are generally associated with changes in either the erythrocyte cytoskeleton [12] or membrane surface proteins, such as components of the glycophorin family, a well-studied group of erythrocyte surface receptors that are known to be under natural selection, likely from malaria [13-15]. To date, however, there is little study of the effects of lipid changes in mediating susceptibility to invasion and whether changes in erythrocyte membrane lipid composition might be associated with changes in efficiency of malaria parasite entry. Several studies have explored the complex relationship between obesity, nutrition and malaria. Obesity has been implicated in being protective against cerebral malaria in a mouse model of malaria infection, although no significant difference in parasitaemia was recorded and the mechanism linking the two is still unclear [16]. Other studies, also in mice, have noted a correlation between malaria infection and outcome in hypoglycaemia and hyperinsulinemia models [17], as well as with mice under calorie restriction [18]. The latter study was found to be due to nutrient sensing by the parasites and subsequent adjustment of multiplication rates through changes in gene expression levels according to nutrient availability. Finally, in humans, assessment of clinical malaria cases in Nigeria noted a negative correlation between malaria infection and serum cholesterol levels [19] though the power of the study was relatively low.

Given the implied linkages between diet, cholesterol levels and malaria and the clear role cholesterol plays in defining membrane properties of cells, the effect of elevated cholesterol levels on erythrocyte biophysical properties and susceptibility to malaria parasite infection was investigated using both an in vitro human Plasmodium falciparum and murine Plasmodium berghei model.

\section{Methods}

\section{Human blood samples and serum cholesterol measurements}

Human erythrocytes $(\mathrm{O}+$, male) for parasite invasion work were obtained from the NHS Blood and Transplant. Approval for collection of clinical human blood samples was granted via the Imperial College Healthcare Tissue Bank, National Research Ethics approval number 17/WA/0161, project ID R18015 and all methods were performed in accordance with the stipulated guidelines and regulations. Blood samples were collected with informed consent from hypercholesterolaemic patients attending the Imperial College London NHS lipid clinic, and from severely hypercholesterolaemic patients undergoing lipoprotein apheraesis as a treatment for homozygous hypercholesterolaemia. EDTA whole blood was collected for parasite assays and parallel measurement of serum cholesterol was performed (Abbott Architect assay, North West London Pathology Blood Sciences Laboratories). Anonymized, normocholesterolaemic EDTA whole blood samples, originating from a primary care setting, were obtained from the hospital blood sciences laboratory. No samples from patients with haemoglobinopathy were included.

\section{Hypercholesterolaemia mouse model and serum cholesterol measurement}

C57/B6 $\mathrm{Ldlr}^{-/-}$mice were obtain directly from the Jackson Laboratory (https://www.jax.org/). The mice were fed either on normal chow (SAFE diet 105) or Western High Fat (Dietex, FAT 21\%, Cholesterol 0.15\%) diets for 8 weeks. Total cholesterol and HDL cholesterol were measured using an enzymatic method in a Siemens Dimensions RxL analyser, following manufacturer's instructions.

\section{Cyclodextrin-complexed cholesterol}

Cholesterol (Sigma-Aldrich) was made up in ethanol at a concentration of $15 \mathrm{mg} / \mathrm{ml}(38.8 \mathrm{mM})$. A $5 \%(38.8 \mathrm{mM})$ 
methyl-beta-cyclodextrin (M $\beta C D)$ stock was made up in MQ-water and heated up on a hotplate stirrer set to $80{ }^{\circ} \mathrm{C} .4 \times 10 \mu \mathrm{l}$ aliquots of the $15 \mathrm{mg} / \mathrm{ml}$ cholesterol stock was added to $400 \mu \mathrm{l}$ of the $\mathrm{M} \beta C D$ stock on the stirrer, leaving $10 \mathrm{~min}$ between each aliquot. The resulting mixture contains $\mathrm{M} \beta \mathrm{CD}$-Cholesterol at a ratio of 10:1. The M $\beta C D$-cholesterol mixture was left stirring on the hotplate for $1 \mathrm{~h}$ (to evaporate the ethanol and allow complex formation) and either used immediately or stored at $-20{ }^{\circ} \mathrm{C}$. Erythrocytes were incubated with $\mathrm{M} \beta \mathrm{CD}$-cholesterol complexes for $30 \mathrm{~min}$ at room temperature while shaking, with concentrations of up to $3.88 \mathrm{mM} \mathrm{M} \beta \mathrm{CD}-388 \mu \mathrm{M}$ cholesterol. Following incubation, erythrocytes were spun down at $800 \times g$ and resuspended into fresh RPMI media before use for further experiments.

\section{Erythrocyte membrane cholesterol measurements}

Membrane cholesterol was quantified using a fluorometric Cholesterol Quantitation Kit (Sigma-Aldrich, UK) according to manufacturer instructions. In short, membranes were extracted with a chloroform-isopropanol-IGEPAL CA-630 solution and spun at $13,000 \times g$ for $10 \mathrm{~min}$, before the organic phase was transferred to a new tube and dried under nitrogen. Samples were put under vacuum for 30 min to remove any residual organic solvents before the lipid films were dissolved in Cholesterol Assay Buffer and vortexed until the mixture was homogenous. Fluorescence intensity was measured using a Tecan MPro 200 fluorescent plate reader (excitation: 535, emission: $587 \mathrm{~nm}$ ).

\section{Parasite in vitro culture}

Plasmodium falciparum parasites (D10-PHG [20]) were maintained in standard culture conditions [21]. Parasites were grown in human $\mathrm{O}+$ erythrocytes at $4 \%$ haematocrit in complete RPMI1640-HEPES media (Sigma-Aldrich) supplemented with $0.3 \%$ L-glutamine, $0.05 \%$ hypoxanthine, $0.025 \%$ gentamicin and $0.5 \%$ Albumax II (Life Technologies). Parasites were grown at $37^{\circ} \mathrm{C}$ in $1 \% \mathrm{O}_{2}, 5 \% \mathrm{CO}_{2}$ in $\mathrm{N}_{2}$ and D10-PHG cultures were supplemented with $25 \mathrm{ng} / \mathrm{ml}$ pyrimethamine and $5 \mu \mathrm{g} / \mathrm{ml}$ blasticidin (Sigma-Aldrich).

\section{Plasmdoium falciparum merozoite invasion assays}

The $P$. falciparum merozoite assay was carried out according to published protocols [22, 23]. For a standard merozoite invasion assay, approximately $90 \mathrm{ml}$ of $5 \%$ synchronized late stage D10-PHG (constitutively expressing green fluorescent protein (GFP)) parasites were magnetically isolated as described in [22], incubated with $10 \mu \mathrm{M}$ of the cysteine protease inhibitor l-transepoxysuccinylleucylamido-(4-guanidino)butane (E64, Sigma-Aldrich) for up to $6 \mathrm{~h}$ under standard culture conditions until at least $50 \%$ of schizonts had developed into parasitophorous vacuole enclosed membrane structures (PEMS) [24]. To obtain free merozoites, PEMS were centrifuged at $800 \times g$ for $5 \mathrm{~min}$ (no brake) and resuspended into a minimum of $750 \mu \mathrm{l}$ of RPMI. The concentrated PEMSsolution is then passed through a $1.2 \mu \mathrm{m}$ Ministart syringe filter (Sartorius Stedim Biotech) to release individual merozoites.

For quantifying erythrocyte invasion rates, $25 \mu \mathrm{l}$ of the filtered merozoite solution was added to a prepared erythrocyte suspension ( $10 \mu \mathrm{l}$ of $1.5 \%$ haematocrit) in a 96 well plate and incubated at $37 \mathrm{C}$ on a shaker (300-500 RPM) for $20 \mathrm{~min}$. An additional sample containing an invasion inhibitor (typically $100 \mathrm{nM}$ cytochalasin D) was included in each experiment and used for accurate gating of the invaded population. Parasites were stained with $100 \mu \mathrm{l}$ of $5 \mu \mathrm{g} / \mathrm{ml}$ Ethidium Bromide (EtBr) for $10 \mathrm{~min}$ at room temperature, washed twice in $100 \mu \mathrm{l}$ phosphate buffered saline (PBS), and resuspended into $60 \mu \mathrm{l}$. Invasion was quantified by flow cytometry, acquiring a total of 100,000 events per well using a BD Fortessa flow cytometer equipped with a high-throughput plate reader. Cells were excited at $488 \mathrm{~nm}$ and emission read between 515 and $545 \mathrm{~nm}$ for GFP positivity and between 600 and 620 for Ethidium Bromide positivity. New ring-stage parasites were quantified based on their GFPpositive, EtBrlow staining profile [23]. Data analysis was carried out in FlowJo v10 by gating on cells based on the side-scatter to forward-scatter profile (i.e. gating out debris), selecting single cells based on the forward-scatter width to area ratio and finally GFP and EtBr profile. Data was visualized in Prism v7 (GraphPad).

\section{Plasmodium berghei merozoite assays}

Female Theiler's Original (TO) mice, 8-10 weeks of age (Envigo, UK) were injected with $200 \mu \mathrm{l}$ glycerol stocks of blood infected with 3\% P. berghei (strain ANKA 507) expressing GFP. When parasitaemia reached approximately $3 \%$, parasites were harvested by cardiac puncture and incubated overnight at $37{ }^{\circ} \mathrm{C}$ in $30 \mathrm{ml}$ complete RPMI-1640 media under low oxygen conditions. The following day schizonts were purified using a magnetic separation column (MACS, Miltenyi Biotec), Purified schizonts were ruptured with a $1.2 \mu \mathrm{m}$ Ministart syringe filter (Sartorius Stedim Biotech) to release individual merozoites and $25 \mu \mathrm{l}$ merozoite solution was added to blood obtained from mice of interest $(10 \mu \mathrm{l}$ at 100,000 cells per $\mu \mathrm{l}$, counted as described below) in a 96 well plate. The culture was incubated for $20 \mathrm{~min}$ on a shaker at $37{ }^{\circ} \mathrm{C}$. Cells were stained and quantified as per the $P$. falciparum merozoite assay'quantification of invasion by flow cytometry' described above. 


\section{Flow cytometry and bead counting}

The counting bead (CountBright Absolute Cell Counting Beads, Thermo-Fisher) solution was made up of $400 \mu \mathrm{l}$ PBS, $50 \mu \mathrm{l}$ counting bead solution and $50 \mu \mathrm{l}$ of $1 \%$ haematocrit blood. To ensure equal number of beads across the samples, a mastermix of PBS-Counting beads was made up first, mixed well and separated into the number of samples required before the cell solution was added to the bead-mix. Analysis was carried out on a BD Fortessa flow cytometer. Cells were excited at $488 \mathrm{~nm}$ and emission read between 515 and $545 \mathrm{~nm}$. 2000 beads were acquired per sample. Using ratiometric analyses based on the number of beads and cells acquired, the number of cells per $\mu \mathrm{l}$ of sample can be calculated. Data analysis was carried out in FlowJo v10 by gating on cells based on based on the forward-scatter and GFP negativity and beads based on their forward scatter profile and GFP positivity.

\section{Flicker spectroscopy}

Flicker spectroscopy was carried out as previously described [10]. Membrane oscillation recordings were taken on a Nikon Ti Microscope (objective lens: Nikon Plan Apo 100× 1.4 N.A oil immersion) using an OrcaFlash4.0 CMOS camera. Approximately 4500 frames were recorded at a frame rate of $150( \pm 10$ frames per second (fps)) and an exposure time of $1 \mathrm{~ms}$. Data analysis was carried out using a custombuilt LabVIEW (National Instruments) program that detects and extracts membrane contours. Fourier transforming gives a fluctuation power spectrum of mean square mode amplitudes hh2(qx, $\mathrm{y}=0$ ) as a function of mode wavenumber (qx). From these data, the bending modulus ( $\mathrm{k}$ ) and tension (s) can be fitted using the following equation:

$$
h\left(q_{x}, y=0\right)^{2}=\frac{1}{L} \frac{k_{B} T}{2 \sigma}\left(\frac{1}{q_{x}}-\frac{1}{\sqrt{\frac{\sigma}{k_{c}}+q_{x}^{2}}}\right)
$$

where $\mathrm{k}_{\mathrm{B}}$ is the Boltzmann constant, $\mathrm{T}$ is temperature, and $L$ is mean circumference of the cell contour [10]. Examples of the full spectra and fitted spectra for human and mouse erythrocytes are shown in Additional file 1: Fig. S1.

\section{Results}

Artificial incorporation of membrane cholesterol inhibits Plasmodium falciparum merozoite invasion

Based on previous findings, demonstrating that a reduction in the erythrocyte bending modulus resulted in an increased merozoite invasion efficiency [10], it was hypothesized that stiffening the erythrocyte membrane by increasing cholesterol content would result in a lower merozoite invasion efficiency. Erythrocytes were incubated in media supplemented with a range of cholesterol concentrations, however, no change in the red cell bending modulus was found (Fig. 1a-d). Methyl- $\beta$-cyclodextrin (M $\beta C D)$ is a compound frequently used to incorporate additional cholesterol into cell membranes. Because of its high affinity for cholesterol, $\mathrm{M} \beta \mathrm{CD}$ can be used directly to extract cholesterol from cell membranes or it can be coupled with cholesterol prior to addition to cells in order to increase cholesterol packing in the target cell membrane [25]. Thus, in an attempt to increase erythrocyte cholesterol content, red cells were incubated with $\mathrm{M} \beta C D$ coupled cholesterol. As expected, a highly significant increase in erythrocyte bending modulus was observed, whilst no significant increase in membrane tension (a measure of cytoskeletal effects [10]) was found at this concentration (Fig. 1e, f). To confirm that additional cholesterol had been incorporated into the cell membranes, cells were washed, lipid membrane extracted, purified, dried and resolubilized to measure cholesterol content. A concentration dependent increase in membrane cholesterol was observed in erythrocytes pre-incubated with $\mathrm{M} \beta \mathrm{CD}$ coupled cholesterol (Fig. 1g). To ensure that experimental samples fell within a linear range, a cholesterol fluorometric standard curve was set up (Fig. 1h). To test whether a cholesterol-dependent increase in bending modulus is negatively correlated with merozoite invasion efficiency, erythrocytes were exposed to various concentrations of $\mathrm{M} \beta \mathrm{CD}$-coupled cholesterol, washed and then incubated with purified merozoites added for $30 \mathrm{~min}$. Invasion efficiency was quantified using flow cytometry and showed a clear linear relationship between cholesterol-dependent increase in bending modulus and merozoite invasion (Fig. 2a-c).

\footnotetext{
(See figure on next page.)

Fig. 1 Incubating red cells with M $\beta C D$ coupled cholesterol leads to incorporation of cholesterol into red cell membranes and increased red cell bending modulus. Repeated attempts to increase red cell cholesterol by incubating cells in media supplemented with cholesterol alone did not result in changes to red cell biophysical properties. Summary of $(\mathbf{a}, \mathbf{c})$ tension $(\sigma)$ and $(\mathbf{b}, \mathbf{d})$ bending modulus $(\kappa)$ values of red cells from two different donors pre-treated with a wide range of cholesterol concentrations. Pre-treatment of red cells with M $B C D$ coupled cholesterol similarly did not affect red cell (e) tension ( $\sigma$ ) but significantly increased red cell (f) bending moduli (K). Each circle represents data from a single cell, and the solid line represents the median. To quantify the red cell cholesterol, first a cholesterol fluorometric standard curve was set up to show the linear range of the cholesterol quantitation assay (h). Red cells were incubated with increasing amounts of M $\beta C D$ coupled cholesterol, washed and lipid membranes purified prior to cholesterol quantification. A concentration dependent increase in the cholesterol content was found in erythrocytes that had been incubated with M $B C D$ coupled cholesterol $(\mathbf{g})$. P values comparing the treatment versus control flicker spectroscopy data were calculated using the Mann-Whitney test (ns not significant; ${ }^{* * *} p<0.0001$ )
} 

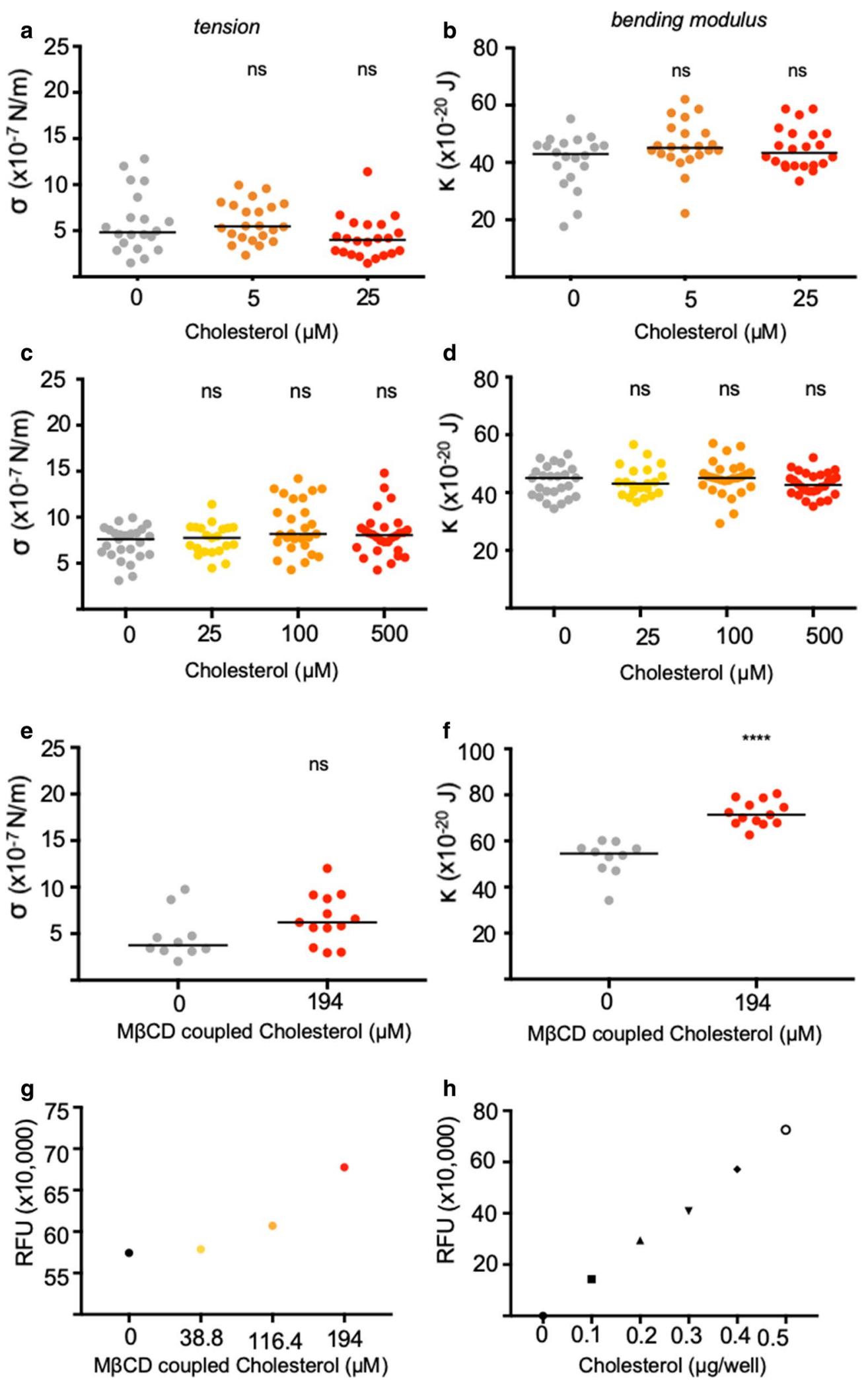


\section{Establishing an in vitro merozoite invasion assay} for Plasmodium berghei

Having established a clear link between cholesterol content, erythrocyte bending modulus and P. falciparum merozoite invasion efficiency, the effect of increased serum cholesterol in vivo was explored to test whether it might partially protect the host from merozoite invasion using the murine malaria model $P$. berghei. Before commencing study of cholesterol effects, a workflow that can isolate invasion events in the mouse malaria model was developed. To date, study of merozoite invasion in $P$. berghei (as opposed to infection in vivo) has lagged behind that of P. falciparum [22] and Plasmodium knowlesi [26] largely because, as an in vivo model, there are few in vitro tools for its long-term propagation and, therefore, ability to isolate synchronous invasion events. Thus, to enable direct measurement of invasion (as opposed to growth) a robust workflow for merozoite isolation and invasion assessment of murine erythrocytes using $P$. berghei in vitro was established. Quantifying murine erythrocyte parasitaemia usually uses flow cytometry based on the nuclear staining of infected cells. The presence of different nucleated cell populations in mouse blood (Howell-Jolly bodies, red cell progenitors as well as leukocytes) necessitates use of a combination of antibodies and stains to allow identification of infected erythrocytes [27]. A further complication arises because of the lack of synchronicity of the parasites in vivo, with invasion occurring over a course of several hours-which can vary between individual animals-making comparison difficult. To overcome these limitations, the in vitro method for quantifying $P$. falciparum merozoite invasion [22] to P. berghei was adapted (Fig. 3). Using green fluorescent protein (GFP)-positive $P$. berghei isolation of synchronous parasites could be ensured that, on maturation, can be magnet separated and $1.2 \mu \mathrm{m}$ filtered to release individual infectious merozoites. Using a 96 well-plate format a fixed volume of free merozoites were added to $10^{6}$ erythrocytes, allowing for $30 \mathrm{~min}$ invasion at $37{ }^{\circ} \mathrm{C}$ while shaking. Staining samples with ethidium bromide (EtBr), samples could then be analysed by flow cytometry. This workflow enabled quantification of an invaded erythrocyte population, which could be gated on the basis of its GFP-positive and low EtBr staining (as the dye does not stain the intra-erythrocytic parasite as efficiently [28]) (Fig. 3).

\section{Plasmodium berghei merozoite invasion efficiency is not affected by increased serum cholesterol in a mouse model of hypercholesterolaemia}

To test whether hypercholesterolaemia does indeed stiffen the erythrocyte membrane and provides some protection against $P$. berghei merozoite invasion, an appropriate mouse model of hypercholesterolaemia was sought. Unlike humans, mice do not efficiently absorb excess cholesterol through diet and are therefore protected from hypercholesterolaemia [29] without perturbation of cholesterol metabolism. Several genetically modified mouse models have been developed to overcome this issue; by far the most commonly used are Low Density Lipoprotein (LDL) receptor knockout (LDL$\mathrm{R}^{-/-}$) and ApoE knockout $\left(\mathrm{ApoE}^{-/-}\right)$strains [30]. Perturbations of either pathway disrupt reverse cholesterol transport leading to excess LDL cholesterol in the circulation. P. berghei merozoite invasion was tested in the hypercholesterolaemia susceptible mouse strains LDL$\mathrm{R}^{-1-}$. Six mice were used, three placed on a standard diet with the other three placed on a high fat diet for 8 weeks before blood was harvested by cardiac puncture and used for quantitative merozoite invasion assays. Using two independent parasite cultures on separate days, no significant difference was found in merozoite invasion efficiency between the standard and high-fat diet groups (Fig. 4a-e). Thus, although the sample size was small, no correlation was found between merozoite invasion efficiency and total plasma cholesterol (Fig. 4f).

\section{Erythrocytes from mice with high serum cholesterol do not show altered biophysical properties}

To explore why serum cholesterol did not correlate with invasion efficiency, as it had in vitro with $P$. falciparum merozoites into erythrocytes with artificially elevated membrane cholesterol, the effect of high fat diet was tested to see whether it resulted in increased serum cholesterol levels and stiffer erythrocyte membranes in LDL- $\mathrm{R}^{-/-}$mice. Plasma cholesterol was quantified and the erythrocyte bending modulus was measured using flicker spectroscopy. The plasma cholesterol and triglyceride levels of $\mathrm{LDL}-\mathrm{R}^{-/-}$mice are summarized in

\footnotetext{
(See figure on next page.)

Fig. 2 Increasing the red cell membrane cholesterol content reduces Plasmodium falciparum invasion efficiency. a Representative flow cytometry profiles highlighting infected erythrocyte populations. Top panel includes negative control (erythrocytes only), and erythrocytes incubated with merozoites in the presence of the Plasmodium invasion inhibitor Cytochalasin D (CytD). b Quantification of P. falciparum invasion efficiency into $\mathrm{M} \beta C D$-cholesterol pre-treated red cells. Values represent mean and standard deviation of triplicate wells. This effect on erythrocyte invasion was reproducible across different blood donors $(\mathbf{c})$. P values comparing the treatment versus control were calculated using the Student's $t$ test $\left({ }^{*} p<0.05\right.$; $\left.{ }^{* *} p<0.01\right)$
} 

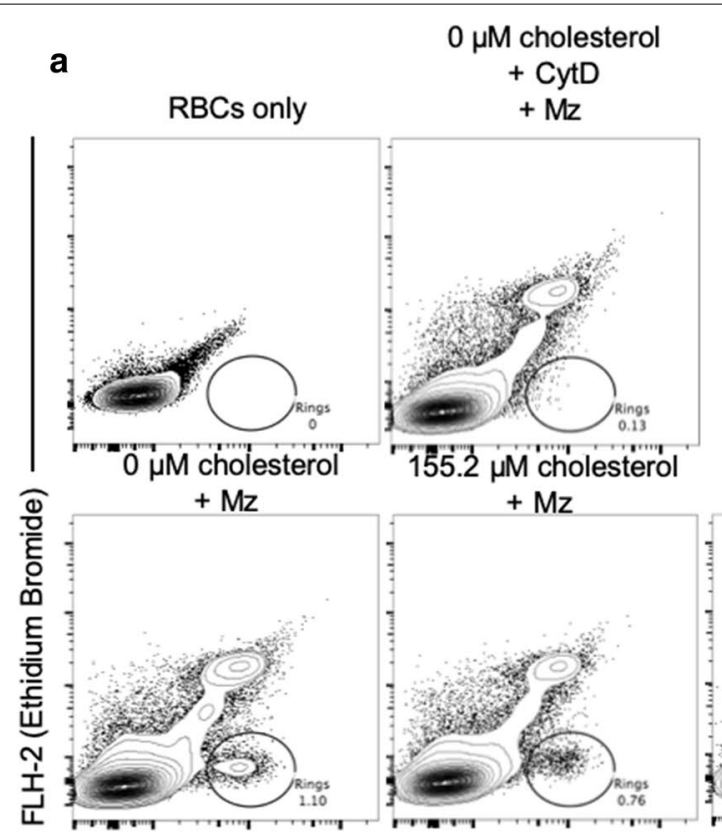

$232.8 \mu \mathrm{M}$ cholesterol $\quad 310.4 \mu \mathrm{M}$ cholesterol

FLH-1 (GFP)

b
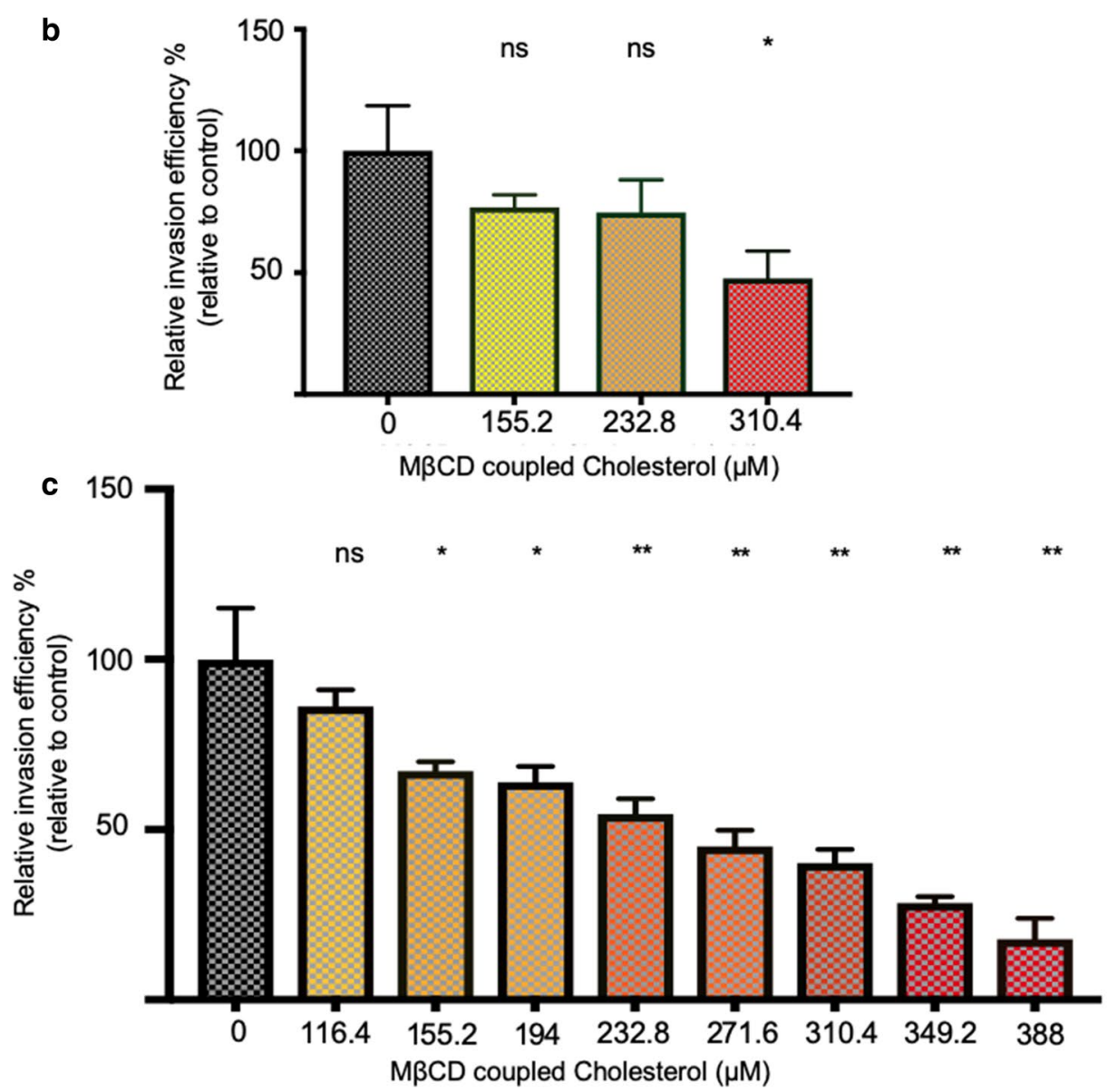


\section{Obtaining blood from mouse of interest and controlling for equal cell numbers}

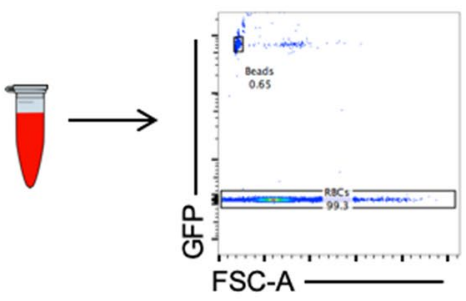

\section{Adjust cell numbers between samples}

FSC-A

\section{Growing and purifying GFP-positive $P$. berghei parasites}

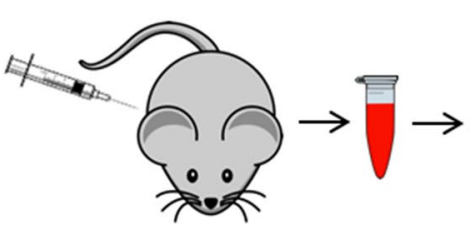

3. Merozoite invasion set-up

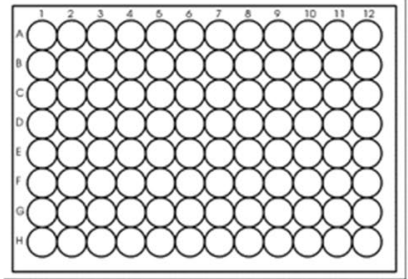

4. Analysis

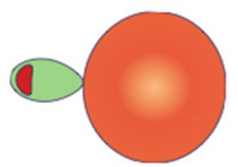

Attached: GFP-positive High $\mathrm{EtBr}$

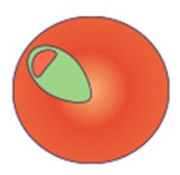

Invaded: GFP-positive Low EtBr

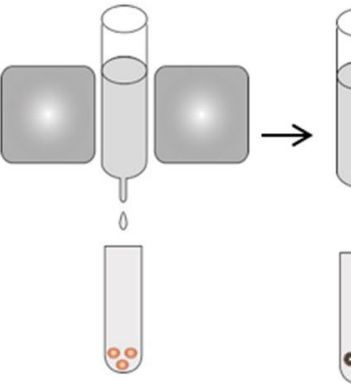

Per sample:

- $10^{6}$ cells per well in $10 \mu \mathrm{l}$ (from (1))

- $20 \mu \mathrm{l}$ of free merozoites (from (2))

- Set up in triplicates

- Shaking for 30 minutes at $37^{\circ} \mathrm{C}$

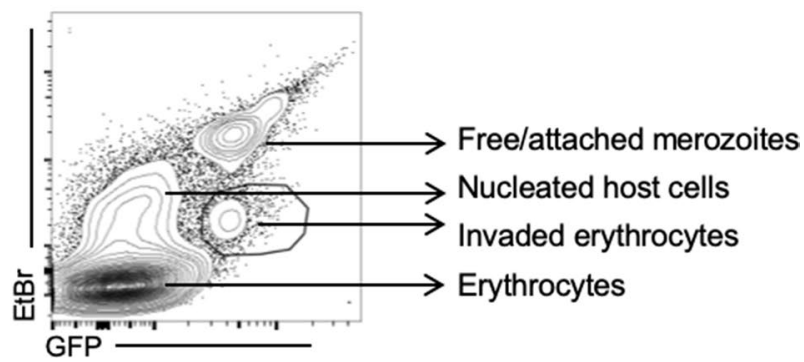

Fig. 3 Workflow of the Plasmodium berghei merozoite assay. Firstly, the blood from the mouse (or mice) of interest is harvested the day prior to the invasion assay either by tail-bleed or cardiac puncture. For the assay to be quantitative, the number of cells need to be kept equal between samples obtained from different mice. This is done using a flow cytometric counting assay. Secondly, GFP-positive P. berghei are injected and grown in mice. At the appropriate parasitaemia, the blood is harvested by cardiac puncture 1 day prior to the invasion assay and incubated at $37^{\circ} \mathrm{C}$ under low oxygen conditions until the parasites have developed into mature schizonts (12-24 h). The mature parasites are then separated from uninfected blood using a MACS magnetic cell separator, and passed through a 1.2 micrometre filter to rupture the parasitophorous vacuolar membrane and release individual merozoites [22]. Next, in a 96 well plate, three wells per mouse, each with $1 \times 10^{6}$ blood cells, are set up before a fixed volume of free merozoites is added to each well. Invasion is allowed to occur for 30 min at $37^{\circ} \mathrm{C}$ while shaking. Finally, the samples are stained with EtBr and analysed by flow cytometry. The population of erythrocytes invaded by parasites is gated on based on their GFP-positive, low EtBr staining, as the dye does not stain the intra-erythrocytic parasite as efficiently [28]

Table 1. Plasma cholesterol levels of mice fed the high fat diet were significantly higher $(\mathrm{p}<0.0001)$ than mice fed the standard diet as expected. Both HDL and LDL levels were elevated, however the biggest increase was observed in the LDL-cholesterol levels. A minimum of
20 erythrocytes from each Chow fed and High Fat Diet (HFD) LDL- $\mathrm{R}^{-1-}$ mice were then analysed using flicker spectroscopy. Tension and bending modulus values of individual erythrocytes are summarized in Fig. 5a, b. Notably, the median tension levels of the erythrocytes 


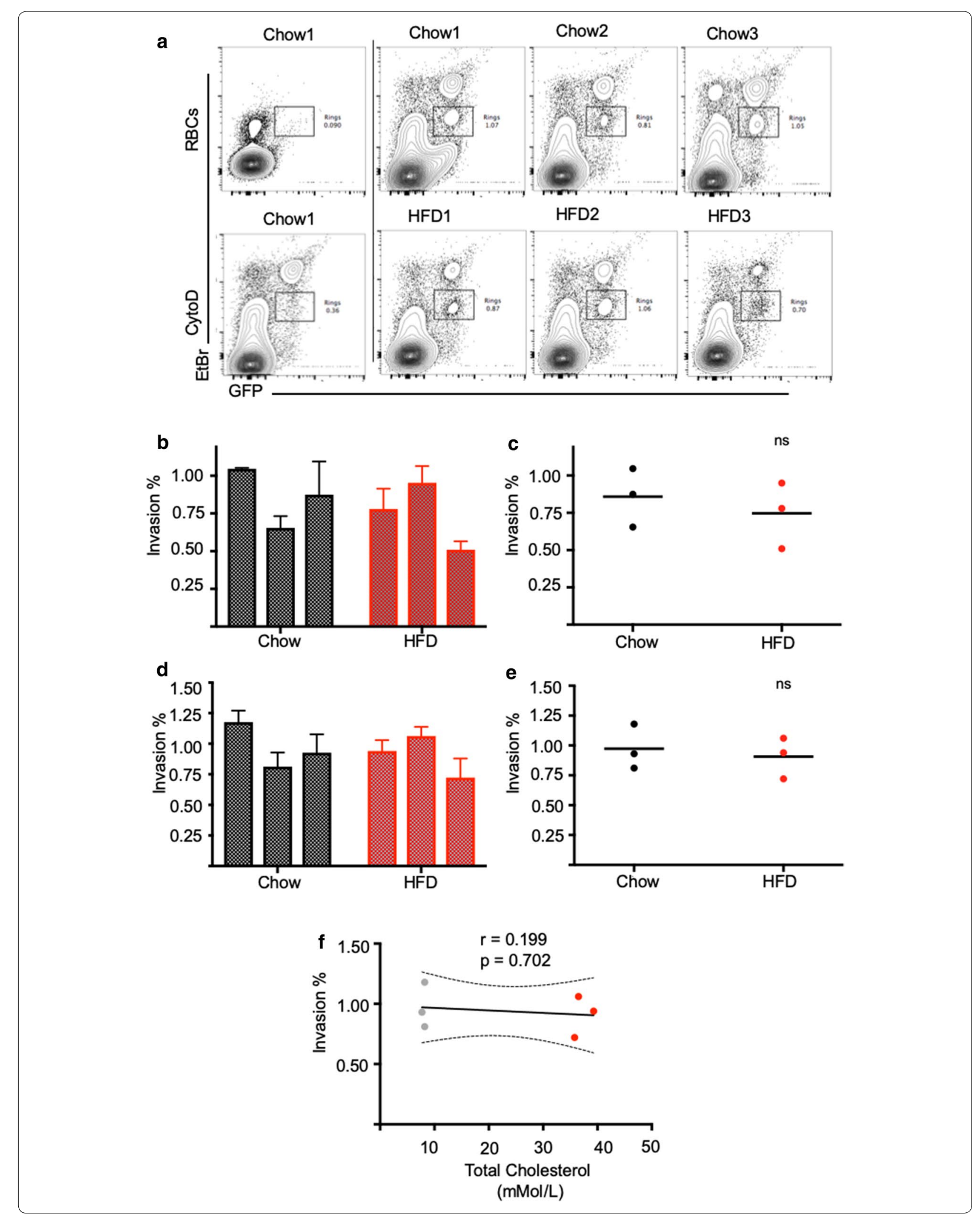


(See figure on previous page.)

Fig. 4 Plasmodium berghei invasion rates obtained from Chow and High-Fat Diet (HFD) LDL- $\mathrm{R}^{-/}$- mice do not differ significantly between chow fed and high fat diets. Invasion rates obtained from Chow and High-Fat Diet (HFD) fed LDL- ${ }^{-1-}$. a Representative flow cytometry profiles highlighting infected red cell populations obtained from mice fed the standard Chow diet (Chow) and high fat diet (HFD). A blood sample in the absence of merozoites and a sample with merozoites and CytD are shown as gating controls. (b, d) Quantification of P. berghei invasion assays carried out on two separate days with newly harvested parasites obtained from different mice. Values represent mean and standard deviation of triplicate wells. The invasion percentages summarized per group are shown for both experiments in $(\mathbf{c}, \mathbf{e})$. Each circle represents the average invasion percentage per sample, line represents mean. No significant differences were found in erythrocyte invasion efficiency between Chow and HFD groups. The correlation between red cell invasion and total plasma cholesterol is shown in ( $\mathbf{f}$ ) along with the Pearson correlation coefficient $(r), p$ value and a linear regression line modelling the correlation with 95\% confidence intervals $(\mathrm{Cl})$. The correlation is not significant $(p>0.05)$. $P$ values comparing $P$. berghei invasion into red cells from HFD or Chow fed mice were calculated using the Student's t test (ns not significant)

\begin{tabular}{|c|c|c|c|c|}
\hline Sample & $\begin{array}{l}\text { Cholesterol } \\
(\mathrm{mmol} / \mathrm{l})\end{array}$ & $\begin{array}{l}\text { Triglycerides } \\
\text { (mmol/l) }\end{array}$ & $\begin{array}{l}\mathrm{HDL} \\
(\mathrm{mmol} / \mathrm{l})\end{array}$ & $\begin{array}{l}\text { LDL } \\
(\mathrm{mmol} / \mathrm{l})\end{array}$ \\
\hline Chow 1 & 8.2 & 1.6 & 1.65 & 5.8 \\
\hline Chow 2 & 8.2 & 1.7 & 1.23 & 6.2 \\
\hline Chow 3 & 7.7 & 2.4 & 2.56 & 4.0 \\
\hline HFD 1 & 39.3 & 4.5 & 2.33 & 34.9 \\
\hline HFD 2 & 36.5 & 4.5 & 2.44 & 32.0 \\
\hline HFD 3 & 35.8 & 4.5 & 2.43 & 31.3 \\
\hline
\end{tabular}

from LDL- $\mathrm{R}^{-/-}$mice were found to be comparable across all samples, ranging between 4.6 and $5.4 \times 10^{-7} \mathrm{~N} / \mathrm{m}$ except for Mouse $\mathrm{C} 2$ for which the median tension is considerably higher at $7.4 \times 10^{-7} \mathrm{~N} / \mathrm{m}$ (Fig. $5 \mathrm{c}$ ). The reason for the higher erythrocyte tension in this mouse is not known. The median bending modulus values were also found to be comparable across the samples, ranging from 34.2 to 38.3 (Fig. 5d). Thus, no significant correlation was found between plasma cholesterol levels and erythrocyte bending modulus. This suggests that the large increase in the plasma cholesterol levels in the HFD fed mice does not significantly impact on the erythrocyte membrane cholesterol in mice.

\section{Plasmodium falciparum merozoite invasion efficiency is not affected by increased serum cholesterol in patients with hypercholesterolaemia}

Since metabolism in mice differs from humans in a number of ways as discussed above, human blood samples from patients with a range of cholesterol levels were collected and tested towards linking plasma serum cholesterol and merozoite invasion efficiency. Blood samples from patients with normal cholesterol levels (up to $5 \mathrm{mmol} / \mathrm{l}$ ) were compared with samples from patients with heterozygous familial hypercholesterolaemia (elevated levels: between 5 and $10 \mathrm{mmol} / \mathrm{l}$ ) as well as samples from patients with homozygous familial hypercholesterolaemia (severely elevated cholesterol levels: above $10 \mathrm{mmol} / \mathrm{l})$. Strikingly, and mimicking that found with mouse models, the level of serum cholesterol again had no significant impact on P. falciparum merozoite invasion efficiency (Fig. 6a-c).

\section{Erythrocytes from patients with high serum cholesterol do not show altered biophysical properties or cholesterol content}

To parallel our studies with murine erythrocytes, the effects of hypercholesterolaemia on erythrocyte biophysical properties were investigated, tension and bending modulus values for individual red cells from each patient sample (Fig. 7a, b), with group summaries shown in Fig. 7c, d. Again, paralleling mouse studies, no significant correlation was found between total serum cholesterol and red cell bending moduli (Fig. 7e). Finally, to investigate the relationship between plasma cholesterol and erythrocyte membrane cholesterol, red cell membranes from each clinical sample were dried, purified and quantified (Fig. 8a, c). No significant correlation was found between erythrocyte membrane cholesterol and plasma serum cholesterol (Fig. 8d). Thus, despite serum cholesterol levels above $10 \mathrm{mmol} / \mathrm{l}$, it appears that human erythrocytes (and likely murine erythrocytes) are naturally buffered from incorporation of excess cholesterol. This would suggest that whilst cholesterol content of the erythrocyte is a direct correlate of malaria parasite invasion efficiency, this is not affected by plasma cholesterol levels.

\section{Discussion}

This work set out to explore the role of erythrocyte lipid content and susceptibility to malaria. A key finding from the work is that artificial manipulation of erythrocyte cholesterol content clearly affects both red cell biophysics and merozoite invasion. By altering the cholesterol content in vitro, the erythrocyte bending modulus (a measure of membrane deformability) can be shown to markedly increase and this negatively correlates with merozoite invasion efficiency. Extending this observation to medical conditions associated with increased cholesterol levels, the question was then asked whether in vivo conditions also lead to stiffer 

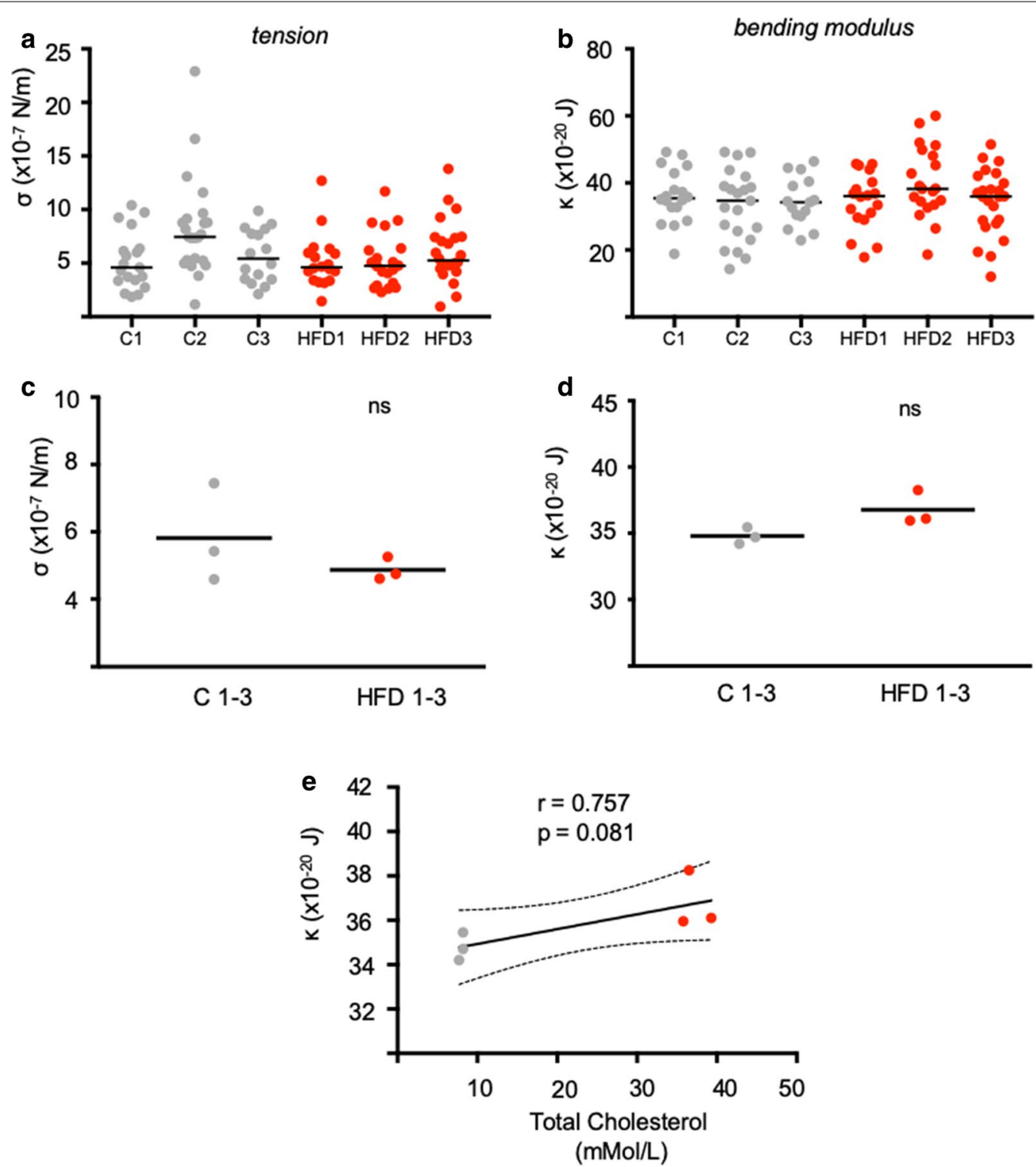

Fig. 5 No significant changes in red cell biophysical properties were found between cells obtained from Chow or HFD-fed LDL-R(-/-) mice. Summary of tension (a) and bending modulus (b) values measured using flicker spectroscopy. Each circle represents data from a single cell, the solid line represents the median. Inter-group comparison of Chow and HFD erythrocyte tension (c) and bending modulus values (d) revealed no significant differences between the groups. Each dot represents the median tension and bending modulus obtained in $\mathbf{a}$, b, solid line represents the mean. The correlation between bending modulus $(k)$ and total plasma cholesterol is shown in $\mathbf{e}$ along with the Pearson correlation coefficient $(r), p$ value and a linear regression line modelling the correlation with $95 \%$ confidence intervals $(\mathrm{Cl})$. The correlation is not significant ( $p>0.05)$. P values comparing the HFD versus control were calculated using the Student's t test (ns not significant)

erythrocytes and an associated reduction in merozoite invasion efficiency. Specifically, the biophysical properties of cells obtained from a murine hypercholesterolaemia model and from human clinical samples with reported hypercholesterolaemia were quantified and subsequently used in quantitative merozoite invasion assays. Strikingly, in both the murine model of hypercholesterolaemia and clinical samples of patients with elevated serum cholesterol, the elevated levels of cholesterol did not correlate with changes in erythrocyte cholesterol content. In line with this, hypercholesterolaemic blood samples showed no comparable changes in malaria parasite infection rates compared to matched controls. Thus, whilst changes in cholesterol 


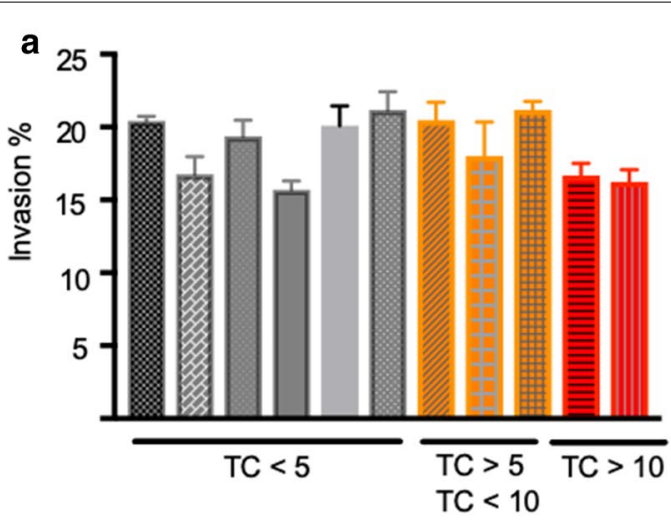

Total Cholesterol $(\mathrm{mMol} / \mathrm{L})$

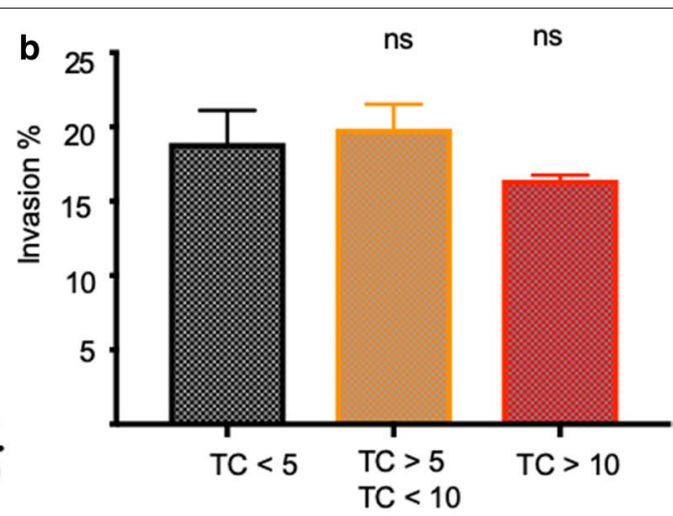

Total Cholesterol ( $\mathrm{mMol} / \mathrm{L})$

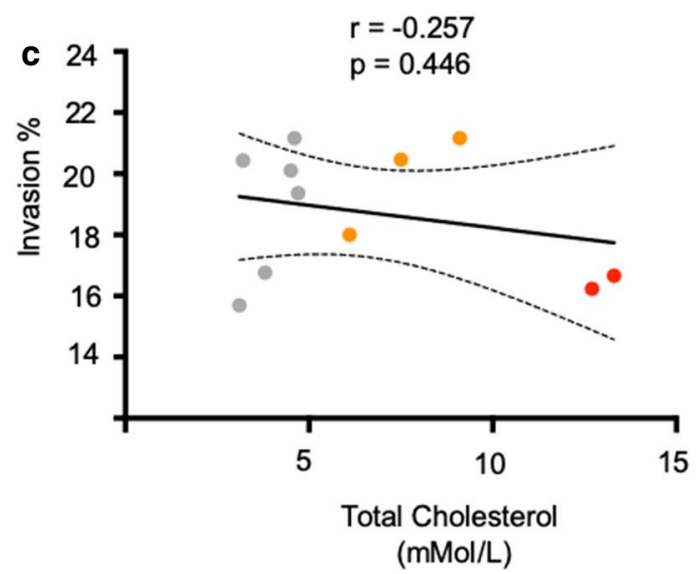

Fig. 6 Plasmodium falciparum invasion rates into red cells obtained from patients with varying total plasma cholesterol (TC) levels do not differ significantly. a Quantification of P. falciparum invasion rates into red cells from patients with low TC $(<5)$, elevated TC $(>5,<10)$ and severely elevated TC (> 10). Values represent mean and standard deviation of triplicate wells. The invasion percentages summarized per group are shown for both experiments in $\mathbf{b}$. The correlation between red cell invasion and total plasma cholesterol is shown in $\mathbf{c}$ along with the Pearson correlation coefficient $(r), p$ value and a linear regression line modelling the correlation with $95 \%$ confidence intervals $(C I)$. The correlation is not significant $(p>0.05)$. $P$ values comparing P. falciparum invasion into red cells from low, elevated and highly elevated TC samples were calculated using the Student's t test (ns not significant)

do directly impact on red cell susceptibility to malaria parasite invasion, the balance of lipid homeostasis in the body likely buffers the red cell from altering its cholesterol content, even in the dramatic situation of hypercholesterolaemia.

Due to the difficulty in obtaining large numbers of fresh blood samples from hypercholesterolaemic patients not on statins, it is possible that very subtle effects on red cell cholesterol content may not be found with the given sample size. Investigating potential effects on erythrocyte membrane cholesterol content within a clinical setting matched the situation found in a mouse hypercholesterolaemia model, suggesting that in vivo buffering of red cell cholesterol does occur. Of note, blood samples of patients with homozygous familial hypercholesterolaemia were included, a rare condition which leads to extremely elevated levels of serum cholesterol. Even in these rare cases, red cell membrane cholesterol did not differ significantly from samples obtained from healthy patients. This therefore implies cholesterol content in the erythrocyte is tightly regulated and not significantly affected by serum cholesterol content.

The lack of correlation between plasma and erythrocyte membrane cholesterol was surprising considering that a similar study carried out in two animal models of hypercholesterolaemia found both plasma and membrane cholesterol levels responding to diet [31], suggesting that erythrocyte membrane cholesterol is dynamic and modifiable under certain conditions. In 

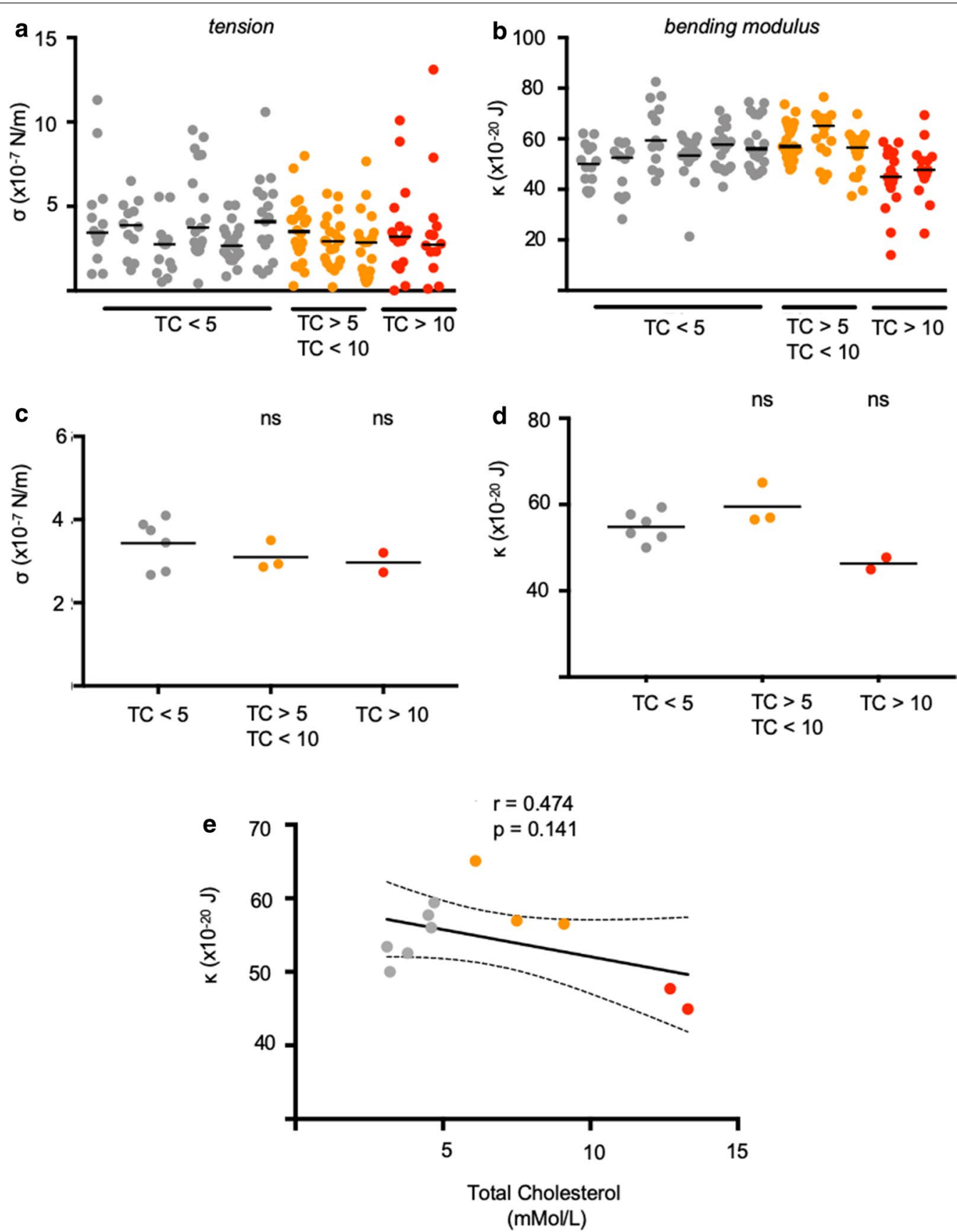

Fig. 7 No significant changes in red cell biophysical properties were found between cells obtained from patients with varying total plasma cholesterol (TC) levels. Summary of tension (a) and bending modulus (b) values measured using flicker spectroscopy. Each circle represents data from a single cell, the solid line represents the median. Inter-group comparison of low TC, elevated and highly elevated TC red cell tension (c) and bending modulus values (d) revealed no significant differences between the groups. Each dot represents the median tension and bending modulus obtained in $\mathbf{a}, \mathbf{b}$, solid line represents the mean. The correlation between bending modulus $(\mathrm{K})$ and total plasma cholesterol is shown in $\mathbf{e}$ along with the Pearson correlation coefficient ( $r), p$ value and a linear regression line modelling the correlation with $95 \%$ confidence intervals (Cl). The correlation is not significant $(p>0.05)$. P values comparing the HFD versus control were calculated using the Student's t test

humans, the picture is not as clear, while both diet [4] and lipid lowering drugs [6] have been shown to affect erythrocyte cholesterol content, other studies report no direct correlation between plasma and cell membrane cholesterol content $[5,32]$. Importantly, how erythrocyte cholesterol content is regulated is not well understood, since erythrocytes neither produce cholesterol de novo nor contain receptors, such as LDL-R, which 

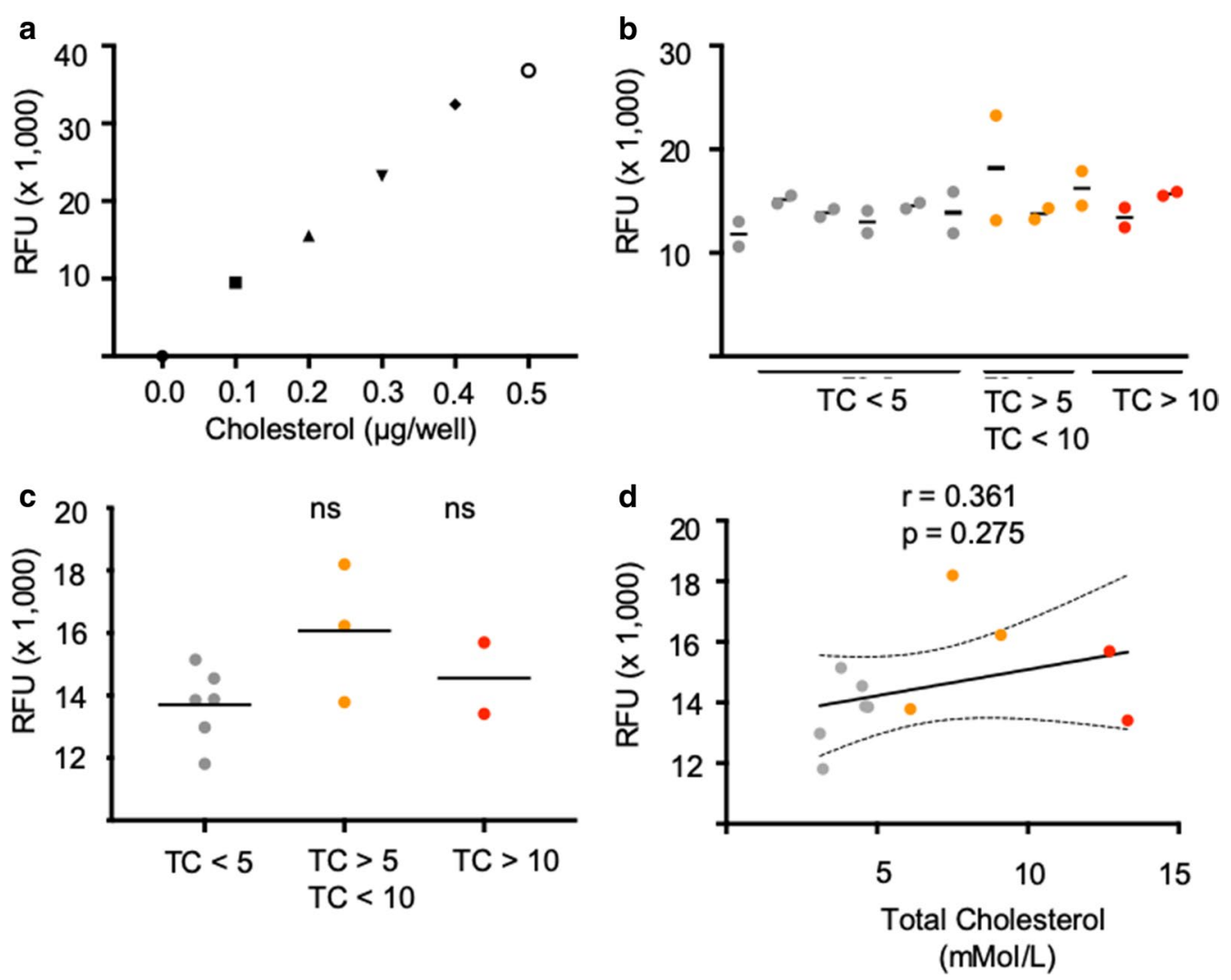

Fig. 8 Plasma cholesterol is not correlated with red cell membrane cholesterol. a Fluorometric cholesterol standard curve. b Red cell membranes from patients with low, elevated and highly elevated total plasma cholesterol were extracted and dried before being quantified using the Cholesterol Quantitation kit (Sigma). c Inter-group comparison of cholesterol membrane measurements revealed no significant differences between the low, medium and high plasma/total cholesterol groups, solid line represents the mean. The correlation between membrane cholesterol and total plasma cholesterol is shown in $\mathbf{d}$ along with the Pearson correlation coefficient ( $r$ ), $p$ value and a linear regression line modelling the correlation with 95\% confidence intervals (CI). The correlation is not significant $(p>0.05)$. P values comparing membrane cholesterol between patient samples were calculated using the Student's t test. RFU Relative fluorescence units

allow uptake of lipoprotein molecules [33]. The most likely mechanism for the induced changes in erythrocyte cholesterol content is a dynamic exchange between plasma and membrane cholesterol [34, 35], with the rate of exchange likely being influenced by the structure and composition of the cell [35].

Despite the lack of changes seen in the samples tested, the question of lipid modulation, its concomitant change in erythrocyte biophysical properties and invasion susceptibility is still pertinent. Manipulating the erythrocyte modulus using different methods (using $7 \mathrm{KC}$ in a previous study and cholesterol enrichment here) both affected Plasmodium parasite invasion efficiency. A consistent working hypothesis is that this results in a direct change in the cell's bending modulus that significantly alters parasite invasion susceptibility. Secondary effects or interactions triggered by the induced enrichment of membrane cholesterol cannot be excluded with full certainty. Cholesterol content has been reported to influence numerous cellular processes for instance changing ligand binding activity through triggering of conformational changes in other lipid groups [36] and altering the membrane dipole potential, thereby affecting protein activity [37].

\section{Conclusions}

The work presented here demonstrates that erythrocyte biophysical properties are markedly affected by direct modulation of lipid, here cholesterol, content. Modulating the biophysical properties in this way negatively impacts merozoite invasion efficiency. Counterintuitively, however, an increase in serum cholesterol in vivo does not significantly affect erythrocyte membrane cholesterol. Thus, classical conditions in which serum cholesterol is markedly elevated, such as hypercholesterolaemia, are not protective directly against the process of merozoite invasion. The impact of lipid changes to the erythrocyte is nonetheless suggestive that other metabolic causes of variation in erythrocyte biophysical 
properties caused by lipid content would still be possible. Future work focusing on sampling and identifying individuals from malaria endemic regions with erythrocytes that have abnormal biophysical properties would be predicted to enable the identification of new protective polymorphisms against malaria disease.

\section{Supplementary information}

Supplementary information accompanies this paper at https://doi. org/10.1186/s12936-019-3016-3.

Additional file 1: Fig. S1. Flicker spectroscopy spectra of human and mouse erythrocytes. (A) A full fluctuation spectrum visualizing height and frequency of membrane oscillations of a human erythrocyte. Higher mode numbers are affected by noise. (B) Modes 5-20 (in red) is the fitted range used to extract tension and bending modulus parameters. A full (C) and (D) fitted (modes 3-18 highlighted in red) mouse erythrocyte fluctuation spectrum.

\section{Abbreviations}

MßCD: methyl- $\beta$-cyclodextrin; GFP: green fluorescent protein; EtBr: ethidium bromide; LDL-R: low density lipoprotein (LDL) receptor; ApoE: apolipoprotein E; HFD: high fat diet.

\section{Acknowledgements}

We thank Jane Srivastava for assistance with flow cytometry (Imperial College Flow Cytometry Facility), Kate Wright and Fernando Sanchez-Roman Teran for assistance with P. falciparum merozoites and Jason L Johnson for generously providing additional mouse models (eventually not used in this study).

\section{Authors' contributions}

All authors participated in the design of experiments and analysis of data. MK, $F A, A M B, Z M$ and $Y L$ performed different components of the P. berghei infection experiments and analysed data. MK JC and BJ collected clinical samples and processed cells for infections. MK performed all in vitro $P$. falciparum work. All authors contributed to the editing of the manuscript. MK and JB wrote the manuscript. All authors read and approved the final manuscript.

\section{Funding}

Tissue sample collection was supported by the National Institute for Health Research (NIHR) Biomedical Research Centre based at Imperial College Healthcare NHS Trust and Imperial College London. M.K. is supported by a PhD scholarship from the UK Medical Research Council (MR/K501281/1). B. J. is supported by an NIHR Clinical Lectureship. Research was directly supported by an Investigator Award from Wellcome (100993/Z/13/Z J.B.). The views expressed are those of the authors and not necessarily those of the NHS, the NIHR or the Department of Health.

\section{Availability of data and materials}

All raw data is available on request.

\section{Ethics approval and consent to participate}

Human erythrocytes $(\mathrm{O}+$, male) for parasite invasion work were obtained from the NHS Blood Transfusion Service. Approval for collection of clinical human blood samples was granted via the Imperial College Healthcare Tissue Bank, National Research Ethics approval number 17/WA/0161, project ID R18015 and all methods were performed in accordance with the stipulated guidelines and regulations. Blood samples were collected with informed consent from hypercholesterolaemic patients attending the Imperial College London NHS lipid clinic, and from severely hypercholesterolaemic patients undergoing lipoprotein apheraesis as a treatment for homozygous hypercholesterolaemia.

\section{Consent for publication}

All authors give their consent for publication.

\section{Competing interests}

The authors declare that they have no competing interests.

\section{Author details}

${ }^{1}$ Department of Life Sciences, Imperial College London, Exhibition Road, South Kensington, London SW7 2AZ, UK. ${ }^{2}$ Division of Diabetes, Endocrinology \& Metabolism, Imperial College London, London, UK. ${ }^{3}$ Division of Cardiovascular Medicine, Department of Medicine, University of Cambridge, Cambridge, UK. ${ }^{4}$ Division of Microbiology and Parasitology, Department of Pathology, University of Cambridge, Cambridge, UK.

Received: 7 July 2019 Accepted: 20 November 2019

Published online: 29 November 2019

\section{References}

1. Chabanel A, Flamm M, Sung KL, Lee MM, Schachter D, Chien S. Influence of cholesterol content on red cell membrane viscoelasticity and fluidity. Biophys J. 1983:44:171-6.

2. Meleard P, Gerbeaud C, Pott T, Fernandez-Puente L, Bivas I, Mitov MD, et al. Bending elasticities of model membranes: influences of temperature and sterol content. Biophys J. 1997;72:2616-29.

3. Henriksen J, Rowat AC, Ipsen JH. Vesicle fluctuation analysis of the effects of sterols on membrane bending rigidity. Eur Biophys J. 2004;33:732-41.

4. Cazzola R, Rondanelli M, Trotti R, Cestaro B. Effects of weight loss on erythrocyte membrane composition and fluidity in overweight and moderately obese women. J Nutr Biochem. 2011;22:388-92.

5. Tziakas DN, Kaski JC, Chalikias GK, Romero C, Fredericks S, Tentes IK, et al. Total cholesterol content of erythrocyte membranes is increased in patients with acute coronary syndrome: a new marker of clinical instability? J Am Coll Cardiol. 2007;49:2081-9.

6. Martinez M, Vaya A, Marti R, Gil L, Lluch I, Carmena R, Aznar J. Erythrocyte membrane cholesterol/phospholipid changes and hemorheological modifications in familial hypercholesterolemia treated with lovastatin. Thromb Res. 1996;83:375-88.

7. White NJ, Pukrittayakamee S, Hien TT, Faiz MA, Mokuolu OA, Dondorp AM. Malaria. Lancet. 2014;383:723-35.

8. Cowman AF, Berry D, Baum J. The cellular and molecular basis for malaria parasite invasion of the human red blood cell. J Cell Biol. 2012;198:961-71.

9. Koch M, Baum J. The mechanics of malaria parasite invasion of the human erythrocyte-towards a reassessment of the host cell contribution. Cell Microbiol. 2016;18:319-29.

10. Koch M, Wright KE, Otto O, Herbig M, Salinas ND, Tolia NH, et al. Plasmodium falciparum erythrocyte-binding antigen 175 triggers a biophysical change in the red blood cell that facilitates invasion. Proc Natl Acad Sci USA. 2017;114:4225-30

11. Sisquella X, Nebl T, Thompson JK, Whitehead L, Malpede BM, Salinas ND, et al. Plasmodium falciparum ligand binding to erythrocytes induce alterations in deformability essential for invasion. Elife. 2017;6:e21083

12. Genton B, Al-Yaman F, Mgone CS, Alexander N, Paniu MM, Alpers MP, et al. Ovalocytosis and cerebral malaria. Nature. 1995;378:564-5.

13. Ndila CM, Uyoga S, Macharia AW, Nyutu G, Peshu N, Ojal J, et al. Human candidate gene polymorphisms and risk of severe malaria in children in Kilifi, Kenya: a case-control association study. Lancet Haematol. 2018;5:e333-45.

14. Baum J, Ward RH, Conway DJ. Natural selection on the erythrocyte surface. Mol Biol Evol. 2002;19:223-9.

15. Malaria Genomic Epidemiology Network, Band G, Rockett KA, Spencer CC, Kwiatkowski DP. A novel locus of resistance to severe malaria in a region of ancient balancing selection. Nature. 2015;526:253-7.

16. Robert V, Bourgouin C, Depoix D, Thouvenot C, Lombard MN, Grellier P. Malaria and obesity: obese mice are resistant to cerebral malaria. Malar J. 2008;7:81.

17. Elased K, Playfair JH. Hypoglycemia and hyperinsulinemia in rodent models of severe malaria infection. Infect Immun. 1994;62:5157-60. 
18. Mancio-Silva L, Slavic K, Grilo Ruivo MT, Grosso AR, Modrzynska KK, Vera $\mathrm{IM}$, et al. Nutrient sensing modulates malaria parasite virulence. Nature. 2017;547:213-6

19. Chukwuocha UM, Eke KN. Malaria parasite status and cholesterol level of malaria patients in parts of the IMO River Basin of Nigeria. Asian Pac J Trop Med. 2011;4:993-6.

20. Wilson DW, Crabb BS, Beeson JG. Development of fluorescent Plasmodium falciparum for in vitro growth inhibition assays. Malar J. 2010;9:152.

21. Trager $W_{1}$ Jensen JB. Human malaria parasites in continuous culture. Science. 1976;193:673-5.

22. Boyle MJ, Wilson DW, Richards JS, Riglar DT, Tetteh KK, Conway DJ, et al. Isolation of viable Plasmodium falciparum merozoites to define erythrocyte invasion events and advance vaccine and drug development. Proc Natl Acad Sci USA. 2010;107:14378-83.

23. Zuccala ES, Satchwell TJ, Angrisano F, Tan YH, Wilson MC, Heesom KJ, et al. Quantitative phospho-proteomics reveals the Plasmodium merozoite triggers pre-invasion host kinase modification of the red cell cytoskeleton. Sci Rep. 2016;6:19766.

24. Salmon BL, Oksman A, Goldberg DE. Malaria parasite exit from the host erythrocyte: a two-step process requiring extraerythrocytic proteolysis. Proc Natl Acad Sci USA. 2001;98:271-6.

25. Zidovetzki R, Levitan I. Use of cyclodextrins to manipulate plasma membrane cholesterol content: evidence, misconceptions and control strategies. Biochim Biophys Acta. 2007;1768:1311-24.

26. Lyth O, Vizcay-Barrena G, Wright KE, Haase S, Mohring F, Najer A, et al. Cellular dissection of malaria parasite invasion of human erythrocytes using viable Plasmodium knowlesi merozoites. Sci Rep. 2018;8:10165.

27. Lelliott PM, Lampkin S, McMorran BJ, Foote SJ, Burgio G. A flow cytometric assay to quantify invasion of red blood cells by rodent Plasmodium parasites in vivo. Malar J. 2014;13:100.

28. Wilson DW, Langer C, Goodman CD, McFadden Gl, Beeson JG. Defining the timing of action of antimalarial drugs against Plasmodium falciparum. Antimicrob Agents Chemother. 2013;57:1455-67.
29. Carter CP, Howles PN, Hui DY. Genetic variation in cholesterol absorption efficiency among inbred strains of mice. J Nutr. 1997;127:1344-8.

30. Zadelaar S, Kleemann R, Verschuren L, de Vries-Van der Weij J, van der Hoorn J, Princen HM, et al. Mouse models for atherosclerosis and pharmaceutical modifiers. Arterioscler Thromb Vasc Biol. 2007;27:1706-21.

31. Sengupta A, Ghosh M. Integrity of erythrocytes of hypercholesterolemic and normocholesterolemic rats during ingestion of different structured lipids. Eur J Nutr. 2011;50:411-9.

32. Dwight JF, Mendes Ribeiro AC, Hendry BM. Effects of HMG-CoA reductase inhibition on erythrocyte membrane cholesterol and acyl chain composition. Clin Chim Acta. 1996;256:53-63.

33. D'Alessandro A, Righetti PG, Zolla L. The red blood cell proteome and interactome: an update. J Proteome Res. 2010;9:144-63.

34. Quarfordt SH, Hilderman HL. Quantitation of the in vitro free cholesterol exchange of human red cells and lipoproteins. J Lipid Res. 1970;11:528-35.

35. Gold JC, Phillips MC. Effects of membrane lipid composition on the kinetics of cholesterol exchange between lipoproteins and different species of red blood cells. Biochim Biophys Acta. 1990;1027:85-92.

36. Lingwood D, Binnington B, Rog T, Vattulainen I, Grzybek M, Coskun U, et al. Cholesterol modulates glycolipid conformation and receptor activity. Nat Chem Biol. 2011;7:260-2.

37. Davis S, Davis BM, Richens JL, Vere KA, Petrov PG, Winlove CP, et al. AlphaTocopherols modify the membrane dipole potential leading to modulation of ligand binding by P-glycoprotein. J Lipid Res. 2015;56:1543-50.

\section{Publisher's Note}

Springer Nature remains neutral with regard to jurisdictional claims in published maps and institutional affiliations.
Ready to submit your research? Choose BMC and benefit from:

- fast, convenient online submission

- thorough peer review by experienced researchers in your field

- rapid publication on acceptance

- support for research data, including large and complex data types

- gold Open Access which fosters wider collaboration and increased citations

- maximum visibility for your research: over $100 \mathrm{M}$ website views per year

At BMC, research is always in progress.

Learn more biomedcentral.com/submissions 